\title{
Cardiovascular and Sympathetic Responses to a Mental Stress Task in Young Patients With Hypertension and/or Obesity
}

\author{
A. GARAFOVA ${ }^{1,4}$, A. PENESOVA ${ }^{1,3}$, E. CIZMAROVA ${ }^{2}$, A. MARKO ${ }^{1,3}$, M. VLCEK ML, $^{1,3}$, \\ D. JEZOVA ${ }^{1}$
}

${ }^{1}$ Institute of Experimental Endocrinology, Slovak Academy of Sciences, Bratislava, ${ }^{2}$ Department of Cardiology, Out-patient Clinic, Karlova Ves, ${ }^{3}$ Center for Molecular Medicine, Slovak Academy of Sciences, Bratislava, ${ }^{4}$ Slovak Medical University, Bratislava, Slovakia

Received March 14, 2014

Accepted August 15, 2014

\section{Summary}

Present study was aimed to investigate sympathetic responses to mental stress with hypothesis that the presence of obesity in patients with hypertension has a modifying effect. Young male subjects, 8 with hypertension grade I, with $B M I<25 \mathrm{~kg} / \mathrm{m}^{2}(\mathrm{HT})$, 10 with hypertension grade $\mathrm{I}$, and $\mathrm{BMI}>30 \mathrm{~kg} / \mathrm{m}^{2}$ (HT OB), 14 healthy controls with $\mathrm{BMI}>30 \mathrm{~kg} / \mathrm{m}^{2}(\mathrm{OB})$, and 13 healthy controls with $\mathrm{BMI}<25 \mathrm{~kg} / \mathrm{m}^{2}$ (C) underwent the Stroop test. ECG was recorded continuously to evaluate heart rate variability (HRV). Blood pressure (BP) and catecholamine concentrations were measured at baseline, at the end of mental stress test and 15 min thereafter. Patients with HT demonstrated increased adrenaline concentrations and enhanced stress-induced noradrenaline release compared to that in healthy controls. In obese subjects, stress-induced increase of systolicBP was lower compared to lean individuals. Stress exposure induced a significant rise in the low frequency power component of HRV, however the increase was lower in the HT OB group compared to C. Obesity in patients with hypertension did not lead to a different reaction in comparison with lean hypertensive subjects. The present data demonstrate higher sympathoadrenal activity in early-stage of hypertension. Obesity is connected with higher resting systolicBP and modifies the HRV response to mental stress.

\section{Key words}

Mental stress • Hypertension • Obesity • Sympathetic activity • Heart rate variability

\section{Corresponding author}

A. Penesova, Laboratory of Human Endocrinology, Institute of Experimental Endocrinology, Slovak Academy of Sciences,
Vlarska 3, 83306 Bratislava, Slovak Republic. Fax: +421 2547749 42. E-mail: adela.penesova@savba.sk

\section{Introduction}

Essential hypertension, obesity and the activity of the sympathetic nervous system are characterized by a complex and yet only partially understood relationships with each other. The mechanisms underlying the association between obesity and arterial hypertension, and in particular the role played in this context by the sympathetic nervous system, are still a matter of considerable debate (Canale et al. 2013).

Disturbances in the pattern of stress related neuroendocrine and autonomic responsiveness is considered to be one of the risk factors of the development of hypertension and other cardiovascular diseases (Treiber et al. 2003, Pierce 2005). Previous studies in patients with hypertension showed higher autonomic/cardiovascular reactivity in response to stress stimuli of different kind, such as physical activity (Lambert and Lambert 2011), insulin induced hypoglycemia (Radikova et al. 2006), cold pain stimulus (Reimann et al. 2012), mental stress tests (Fossum et al. 2004), and public speaking (Palatini et al. 2011).

Only few studies investigated cardiovascular response to stress in early stage of hypertension (HT) development. Schwartz et al. (2011) found that prehypertension elicited a more dramatic pressor response to mental stress (arithmetic test) compared to that in normotensive subjects. On the other hand, plasma noradrenaline levels in response to stressors (cold pressor 
test or a mental arithmetic test) were comparable in young borderline hypertensive men and the control subjects (Matsukawa et al. 1991).

Next to HT, an excess weight is established as a major risk factor for cardiovascular diseases, particularly in young individuals (Trachta et al. 2014). Psychosocial stress has been hypothesized to contribute to the obesityrelated increase of blood pressure (Lambert et al. 2010).

Human obesity may be associated with a state of adrenergic overdrive. Several studies have attempted to investigate whether and to what extent sympathetic activation is a hallmark of the autonomic profile of the obese state. A meta-analysis (Young and Macdonald 1992), although suggestive for a hyperadrenergic state, did not permit any definite conclusion on this issue to be drawn.

In spite of the known interrelationships between stress-induced sympathetic activation and HT, as well as stress-induced sympathetic activation and obesity, the human studies considering all these topics simultaneously are very scarce. Previous studies were done in very variable groups of patients with HT. Therefore the present study investigated cardiovascular and catecholamine responses to a mental stress test in welldefined groups of young patients, non-smokers with early stage of HT with and without obesity in comparison to healthy controls. The main hypothesis is that the presence of obesity in patients with diagnosed HT has a modifying effect on the cardiovascular and catecholamine responses to a mental stress task.

\section{Subjects and Methods}

\section{Subjects}

Forty-five male volunteers in the age of 18-35 years participated in the study. According to the diagnosis of HT and the values of the body mass index (BMI) subjects were divided into four groups: 1. eight volunteers fulfilling criteria for grade I HT (ESH/ESC 2003) and had BMI less than $25 \mathrm{~kg} / \mathrm{m}^{2}$ (HT); 2. ten obese subjects with grade I HT with BMI more than $\geq 30 \mathrm{~kg} / \mathrm{m}^{2}$ (HT OB); 3. fourteen obese otherwise healthy males $\left(\mathrm{BMI} \geq 30 \mathrm{~kg} / \mathrm{m}^{2}, \mathrm{OB}\right)$; and 4 . thirteen healthy controls with BMI less than $25 \mathrm{~kg} / \mathrm{m}^{2}$ (C). The patients were recruited from the registry of the Department of Cardiology Out-patient Clinic Karlova Ves, Slovakia. The diagnosis of HT was confirmed by 24-h blood pressure monitoring. Secondary HT was excluded by routine physical examination and laboratory testing (blood and urine analysis).

All subjects studied were non-smokers, had negative history of endocrine disorders, diabetes or other chronic diseases and were without any current medication including antihypertensive therapy for at least 10 days before the examination. Basic clinical characteristic of all study subjects is given in the Table 1 .

Table 1. Clinical characteristic of study subjects.

\begin{tabular}{|c|c|c|c|c|c|c|}
\hline & $\begin{array}{c}C \\
(n=13)\end{array}$ & $\begin{array}{c}\text { HT } \\
(n=8)\end{array}$ & $\begin{array}{c}\text { OB } \\
(n=14)\end{array}$ & $\begin{array}{c}\text { HT OB } \\
(n=10)\end{array}$ & $\begin{array}{c}\text { p value } \\
\text { for factor } \\
\text { HT dg } \\
\text { (ANOVA) }\end{array}$ & $\begin{array}{c}\text { p value } \\
\text { for factor } \\
\text { OB } \\
\text { (ANOVA) }\end{array}$ \\
\hline Age (years) & $23 \pm 5$ & $23 \pm 3$ & $27 \pm 5$ & $28 \pm 4$ & ns & $<0.05$ \\
\hline$B M I\left(k g / m^{2}\right)$ & $22.0 \pm 1.8$ & $23.4 \pm 2.4$ & $34.0 \pm 3.9$ & $34.4 \pm 3.6$ & ns & $<0.001$ \\
\hline Body fat percentage (\%) & $16 \pm 5$ & $21 \pm 5$ & $33 \pm 7$ & $36 \pm 6$ & ns & $<0.001$ \\
\hline Waist circumference (cm) & $83 \pm 6$ & $85 \pm 9$ & $111 \pm 8$ & $109 \pm 8$ & ns & $<0.001$ \\
\hline SBP baseline $(\mathrm{mm} \mathrm{Hg})$ & $123 \pm 16$ & $141 \pm 13$ & $128 \pm 9$ & $147 \pm 11$ & $<0.001$ & $<0.05$ \\
\hline DBP baseline ( $\mathrm{mm} \mathrm{Hg}$ ) & $66 \pm 8$ & $78 \pm 10$ & $71 \pm 10$ & $84 \pm 10$ & $<0.001$ & ns \\
\hline Heart rate baseline $(1 / \mathrm{min})$ & $71 \pm 14$ & $77 \pm 9$ & $70 \pm 12$ & $80 \pm 11$ & $<0.01$ & ns \\
\hline Adrenaline $(\mathrm{pg} / \mathrm{ml})$ & $47 \pm 33$ & $87 \pm 77$ & $37 \pm 15$ & $72 \pm 40$ & $<0.01$ & ns \\
\hline Noradrenaline $(\mathrm{pg} / \mathrm{ml})$ & $292 \pm 85$ & $295 \pm 67$ & $296 \pm 70$ & $331 \pm 10$ & ns & ns \\
\hline
\end{tabular}

Data are expressed as mean \pm S.D. OB - obesity, HT dg - HT diagnosis, BMI - body mass index, SBP - systolic blood pressure, DBP diastolic blood pressure. $\mathrm{C}$ - healthy controls with $\mathrm{BMI}<25 \mathrm{~kg} / \mathrm{m}^{2}, \mathrm{HT}$ - patients with hypertension and $\mathrm{BMI}<25 \mathrm{~kg} / \mathrm{m}^{2}, \mathrm{HT} \mathrm{OB}-$ patients with hypertension and $\mathrm{BMI} \geq 30 \mathrm{~kg} / \mathrm{m}^{2}, \mathrm{OB}$ - obese otherwise healthy subjects with $\mathrm{BMI} \geq 30 \mathrm{~kg} / \mathrm{m}^{2}$ 
All subjects gave informed written consent and the study was approved by the Ethics Committee of the Bratislava Self-Governing Region, Bratislava, Slovakia in agreement with the ethical guidelines of the Declaration of Helsinki as revised in 2000.

\section{Study design}

Examination started in the morning at 08:00 AM. The subjects were asked to keep $12 \mathrm{~h}$ fasting and restrain stress and physical activity $24 \mathrm{~h}$ before the study. Upon the arrival in the Out-patient clinic, baseline personal history was taken and body weight, height and waist circumference were measured. Thereafter the cubital vein was cannulated (Terumo Europe N.V., Leuven, Belgium) and subjects rested for $30 \mathrm{~min}$ in a comfortable chair to avoid acute stress from venipuncture.

Continuous ECG and respiratory movements were recorded during the whole procedure (PowerLab, ADInstruments Pty Ltd, Bella Vista, NSW, Australia). Heart rate variability (HRV) analysis (Chart HRV modul, ADInstruments Pty Ltd) was performed in $5 \mathrm{~min}$ recordings before, during and after the Stroop test. Following HRV parameters were calculated: total power (TP) in range $0.00-0.40 \mathrm{~Hz}$, low frequency power (LF) in range $0.04-0.15 \mathrm{~Hz}$, high frequency power (HF) in range 0.15-0.40 Hz, LF/HF ratio, and LF and HF powers in normalized units (LFnu, HFnu). HF parameter reflects mainly respiratory sinus arrhythmia as an index of cardiac vagal control, LF is determined by both sympathetic and parasympathetic activity and provides an index not of cardiac sympathetic tone but of baroreflex function, LF/HF ratio may reflect a cardiac sympathovagal balance (Vlcek et al. 2008, Goldstein et al. 2011). If respiratory rhythm at the time of measurement was less than $9 / \mathrm{min}$, or the record had more than 2 extrasystoles per minute, the ECG sample was excluded.

Blood pressure (Dinamap Vital Sign Monitor, model 845 XT, Criticon X, Inc., Tampa, FL, USA) was measured on the left arm at the time of blood collections. The HRxsystolic BP product was calculated as multiplication of HR and systolic BP.

The Stroop test, used and described in our previous studies (Hlavacova et al. 2008, Jezova et al. 2013), was applied as a mental stressor. The test is based on the interference between the words and the colors and consists of four subtests. Participants were asked to read a sample color words printed in black at first, then the printed colors. Finally they took a sample color words printed in colored fonts, which were incongruent with respect to the color word itself. They were asked to name the color of printed words at first and in the last subtest they were asked to name a color font of word and to read printed word in alternation. Throughout the mental task, the subjects were given instructions by the examiner to work quickly but try not to make any mistakes. The total duration of the mental stress procedure was $10 \mathrm{~min}$.

Blood samples were collected before (0 $\mathrm{min})$, at the end of the Stroop test and once again after $15 \mathrm{~min}$ of rest after the test was completed. Blood was drawn into polyethylene tubes with heparin as anticoagulant and immediately cooled in ice. After centrifugation at $4{ }^{\circ} \mathrm{C}$, all plasma aliquots were stored at $-70{ }^{\circ} \mathrm{C}$ until assayed. Plasma epinephrine and norepinephrine concentrations were measured with commercially available enzyme linked immunosorbent assay kits (Demeditec Diagnostics GmbH, Kiel, Germany).

\section{Statistical analysis}

To determine differences in basal parameters and changes during stress and recovery among study groups with identification of influencing factors analysis of variance (ANOVA) was used. General Linear Model repeated measures (GLM-RM) procedure was used to determine main effects for factors HT diagnosis and obesity on measured parameters responses during stress test. Because of high interindividual variability, frequency-domain HRV parameters were logarithmically transformed for statistical testing (lnLF, lnHF; Lin et al. 2012). Pearson's correlation analysis was computed to determine relationship between the parameters measured. Statistical evaluation was performed using the SPSS 11.5 program (SPSS Inc., Chicago, IL, USA). The results are expressed as the mean \pm SEM, unless otherwise specified. Differences were considered significant at $\mathrm{p}<0.05$.

\section{Results}

General and anthropometric characteristics of the study population are shown in Table 1 . OB and HT OB were older than other groups $(\mathrm{p}=0.03)$. As expected there were differences in BMI, waist circumference and percentage of body fat (BF) among those with and without obesity $(\mathrm{p}<0.001)$.

\section{Baseline parameters}

Statistical analysis revealed significant main 
effect of HT diagnosis for baseline systolic blood pressure $(\mathrm{SBP})(\mathrm{F}=13.128 ; \mathrm{p}=0.001)$, diastolic blood pressure $(\mathrm{DBP})(\mathrm{F}=12.348 ; \mathrm{p}=0.001)$ and heart rate $(\mathrm{HR})$ $(\mathrm{F}=4.785, \mathrm{p}=0.034)$. HT patients had higher SBP, DBP as well as HR than the normotensive controls. There was also a significant effect of the main factor obesity for SBP $(F=4.275, p=0.045)$. Obese subjects had higher SBP, but not DBP and HR than the lean subjects (Table 1). The HRxSBP product showed main effect of HT diagnosis $(\mathrm{F}=11.280, \mathrm{p}=0.002)$.

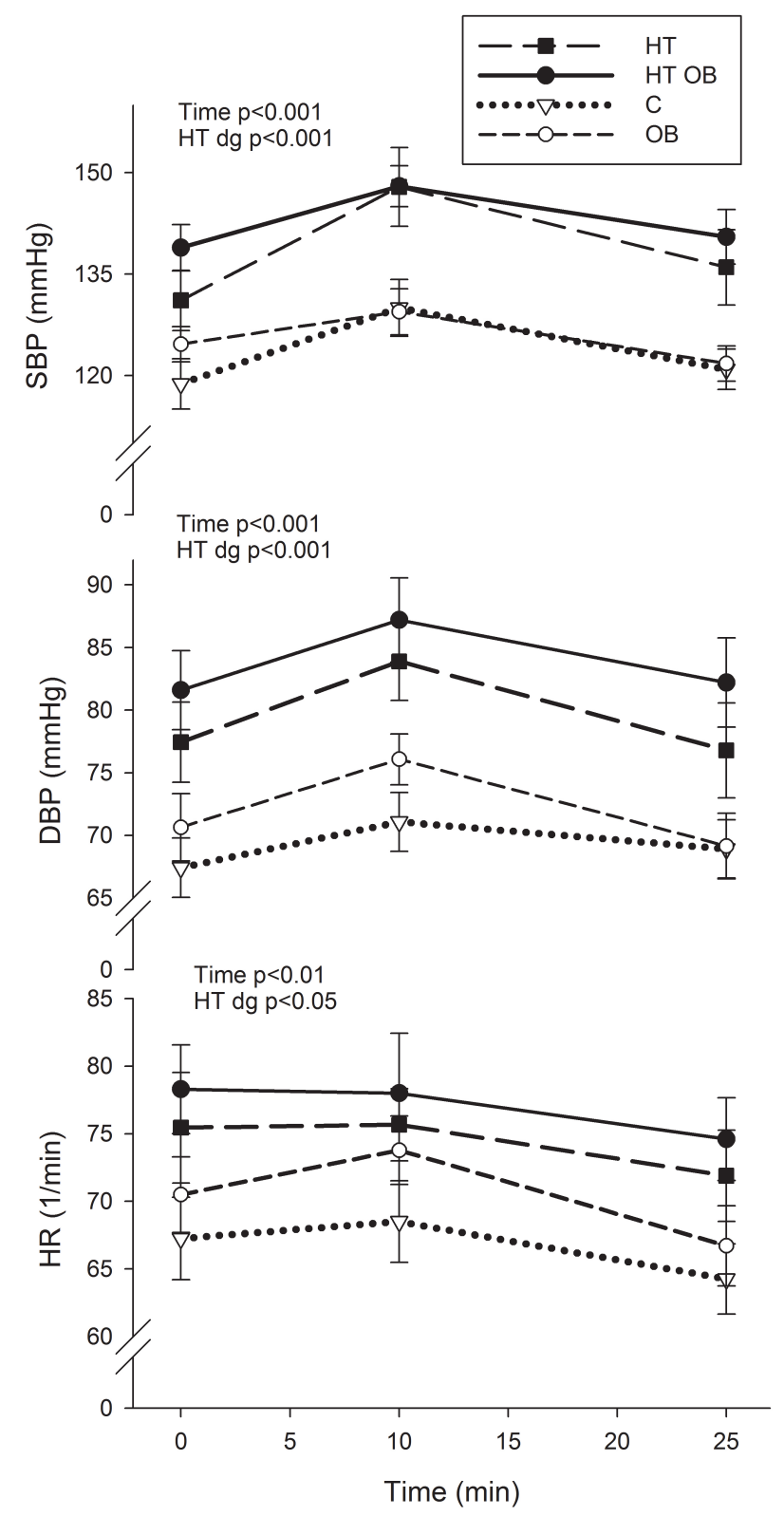

Fig. 1. Blood pressure and heart rate during mental stress test. Healthy controls with $\mathrm{BMI}<25 \mathrm{~kg} / \mathrm{m}^{2}$ (C) - triangles and dotted line, patients with hypertension and $B M I<25 \mathrm{~kg} / \mathrm{m}^{2}(\mathrm{HT})-$ squares and long dash line, patients with hypertension and $\mathrm{BMI} \geq 30 \mathrm{~kg} / \mathrm{m}^{2}$ (HT OB) - circles and solid line, obese otherwise healthy subjects with $B M I \geq 30 \mathrm{~kg} / \mathrm{m}^{2}(\mathrm{OB})$ - open circles and short dash line. HT dg - hypertension diagnosis
The results of statistical analysis showed significant main effect of HT diagnosis on baseline plasma adrenaline $(\mathrm{F}=8.345, \mathrm{p}=0.006)$ but not on noradrenaline concentrations (Table 1). The HT patients had higher adrenaline than the normotensive controls.

The results showed significant main effect of HT diagnosis on baseline LF power $(\mathrm{F}=10.302, \mathrm{p}=0.003)$. The analysis by Tukey post hoc test revealed that the values of LF power were significantly lower in HTOB group $(p=0.007)$ than in controls (Table 2). However, there were no effects of HT diagnosis or obesity on other baseline HRV parameters (HF power, LFnu, HFnu, $\mathrm{LF} / \mathrm{HF}$ ).

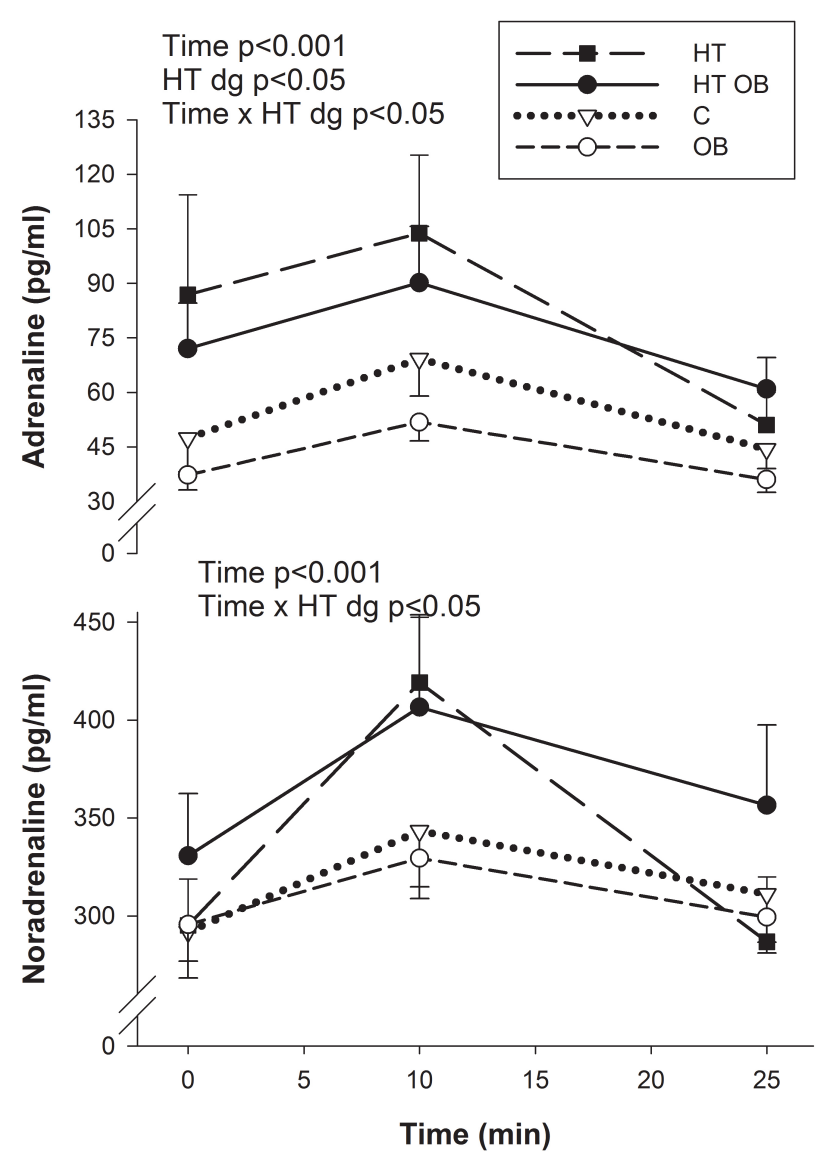

Fig. 2. Adrenaline and noradrenaline levels during mental stress test. Healthy controls with $\mathrm{BMI}<25 \mathrm{~kg} / \mathrm{m}^{2}$ (C) - triangles and dotted line, patients with hypertension and $\mathrm{BMI}<25 \mathrm{~kg} / \mathrm{m}^{2}(\mathrm{HT})-$ squares and long dash line, patients with hypertension and $\mathrm{BMI} \geq 30 \mathrm{~kg} / \mathrm{m}^{2}$ (HT OB) - circles and solid line, obese otherwise healthy subjects with $B M I \geq 30 \mathrm{~kg} / \mathrm{m}^{2}(\mathrm{OB})$ - open circles and short dash line. HT dg - hypertension diagnosis

\section{Responses to the mental stress task}

As revealed by general linear model repeated measures procedure, SBP (Fig. 1) increased during stress test in all groups in time $(\mathrm{F}=22.554, \mathrm{p}<0.001)$, with the 
significant main effect of HT diagnosis ( $\mathrm{F}=23.888$, $\mathrm{p}<0.001)$. Similarly, DBP increased during mental stress test in time $(\mathrm{F}=14.762, \mathrm{p}<0.001)$, with significant main effect of HT diagnosis $(F=16.135, p<0.001)$. There was a significant main effect of HT diagnosis $(\mathrm{F}=5.004$, $\mathrm{p}=0.031)$ and a significant effect of time $(\mathrm{F}=6.810$, $\mathrm{p}=0.003$ ) for the HR, which increased in response to the Stroop test in all subjects. There was no significant main effect for the factor obesity or any interaction between the factors in any of the parameters mentioned.

Adrenaline concentrations (Fig. 2) changed during the stress test significantly in time $(F=24.121$, $\mathrm{p}<0.001$ ), with allover higher values in subjects with presence of HT $(\mathrm{F}=9.400, \mathrm{p}=0.004)$ and the response was affected by HT diagnosis (time x HT diagnosis $\mathrm{F}=3.746$, $\mathrm{p}=0.028$ ), with no effect of obesity. Noradrenaline concentrations increased in all subjects in response to the Stroop test in time $(\mathrm{F}=24.683, \mathrm{p}<0.001)$ and there was a significant time $\mathrm{x}$ HT diagnosis interaction $(\mathrm{F}=4.769$, $p=0.016$ ), without effect of obesity.
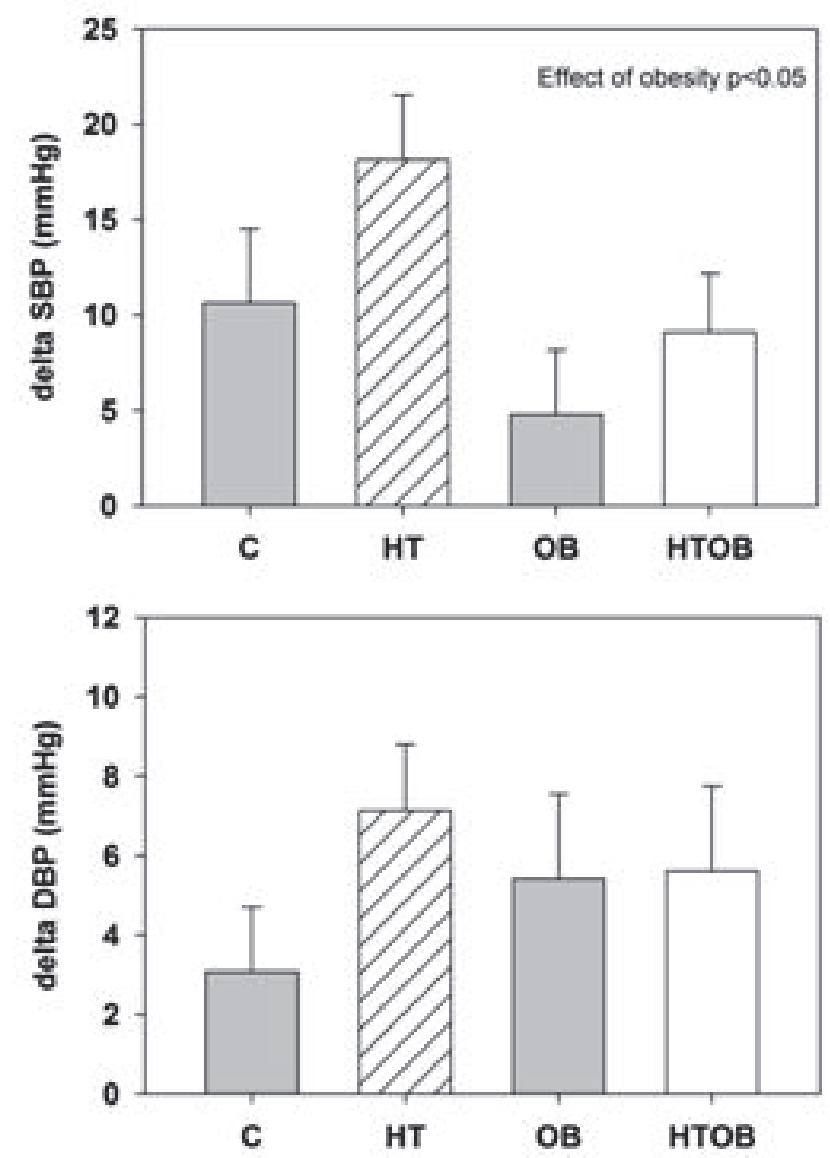

Because of a relatively high variability of the values as well as the differences in baseline blood pressure, the results were evaluated also in the form of stress-induced increases (value immediately after stress procedure minus value before the test, $\Delta$ ). This approach revealed a significant main effect of the factor obesity for $\triangle$ SBP $(\mathrm{F}=4.105, \mathrm{p}=0.049)$. The stress-induced increase in SBP was lower in obese subjects compared to that in lean individuals irrespective of the HT diagnosis (Fig. 3). No significant differences were observed in stressinduced changes in the DBP (Fig. 3) and HR (data not shown). Exposure to mental stress task induced significant changes in noradrenaline concentrations. Twoway ANOVA showed a significant main effect of HT diagnosis on $\Delta$ noradrenaline $(F=6.543, p=0.014)$ without significant effect of obesity. The HT patients had higher $\Delta$ noradrenaline than the normotensive controls. In the case of $\Delta$ adrenaline, the exposure to mental stress induced similar responses in all groups (Fig. 3).
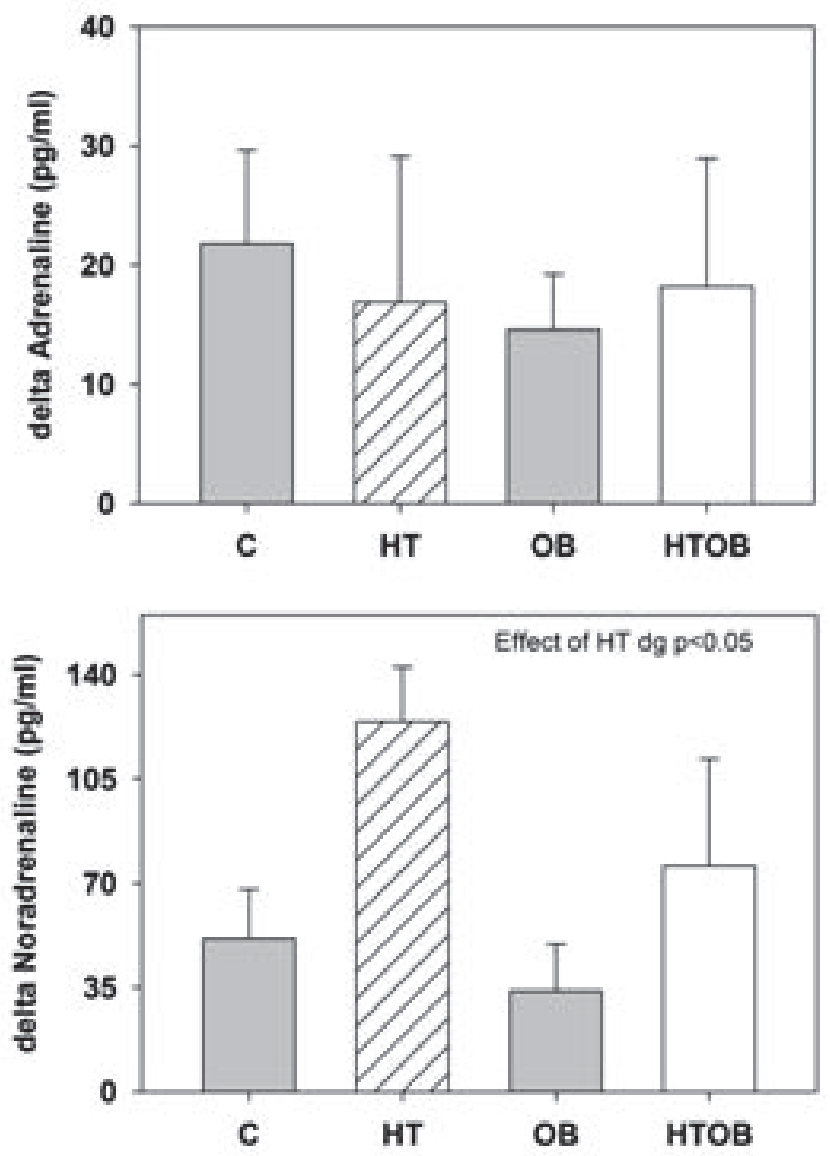

Fig. 3. Delta of SBP, DBP, adrenaline and noradrenaline induced by mental stress. SBP - systolic blood pressure, DBP - diastolic blood pressure, $\mathrm{HT} \mathrm{dg}$ - hypertension diagnosis, $\mathrm{C}$ - healthy controls with $\mathrm{BMI}<25 \mathrm{~kg} / \mathrm{m}^{2}, \mathrm{HT}$ - patients with hypertension and $\mathrm{BMI}<25 \mathrm{~kg} / \mathrm{m}^{2}$, $\mathrm{HT} \mathrm{OB}$ - patients with hypertension and $\mathrm{BMI} \geq 30 \mathrm{~kg} / \mathrm{m}^{2}, \mathrm{OB}$ - obese otherwise healthy subjects with $\mathrm{BMI} \geq 30 \mathrm{~kg} / \mathrm{m}^{2}$ 
Table 2. HRV responses to the mental stress task (unadjusted means \pm SEM).

\begin{tabular}{lcccc}
\hline & $\begin{array}{c}\mathbf{C} \\
(\mathbf{n = 1 3 )}\end{array}$ & $\begin{array}{c}\mathbf{H T} \\
\mathbf{( n = 8 )}\end{array}$ & $\begin{array}{c}\text { OB } \\
(\mathbf{n = 1 4 )}\end{array}$ & $\begin{array}{c}\text { HT OB } \\
(\mathbf{n = 1 0})\end{array}$ \\
\hline InLF pre-Stroop $\left(\mathrm{ms}^{2}\right)$ & $7.7 \pm 0.7$ & $6.9 \pm 0.9$ & $7.2 \pm 0.9$ & $6.6 \pm 0.7^{* *}$ \\
InLF post-Stroop $\left(\mathrm{ms}^{2}\right)$ & $8.0 \pm 0.6$ & $6.9 \pm 0.9$ & $7.3 \pm 0.8$ & $6.7 \pm 0.7$ \\
InHF pre-Stroop $\left(\mathrm{ms}^{2}\right)$ & $6.9 \pm 1.3$ & $5.7 \pm 1.2$ & $6.0 \pm 1.5$ & $5.6 \pm 0.5$ \\
lnHF post-Stroop $\left(\mathrm{ms}^{2}\right)$ & $7.1 \pm 1.1$ & $5.7 \pm 1.1$ & $5.9 \pm 1.3$ & $5.7 \pm 1.1$ \\
LF/HF pre-Stroop & $3.2 \pm 2.6$ & $3.9 \pm 2.6$ & $5.4 \pm 4.3$ & $3.0 \pm 1.1$ \\
LF/HF post-Stroop & $2.9 \pm 1.6$ & $3.7 \pm 1.9$ & $5.6 \pm 4.5$ & $3.2 \pm 1.6$ \\
\hline
\end{tabular}

InLF - low frequency power, InHF - high frequency power, C - healthy controls with $\mathrm{BMI}<25 \mathrm{~kg} / \mathrm{m}^{2}, \mathrm{HT}$ - patients with hypertension and $\mathrm{BMI}<25 \mathrm{~kg} / \mathrm{m}^{2}, \mathrm{HT}$ OB - patients with hypertension and $\mathrm{BMI} \geq 30 \mathrm{~kg} / \mathrm{m}^{2}, \mathrm{OB}$ - obese otherwise healthy subjects with $\mathrm{BMI} \geq 30 \mathrm{~kg} / \mathrm{m}^{2}$. $* * \mathrm{p}<0.01$ versus appropriate $\mathrm{C}$

The statistical analysis with repeated measures showed a significant main effect of time $(\mathrm{F}=36.0$, $\mathrm{p}=0.012)$ and HT diagnosis $(\mathrm{F}=9.970, \mathrm{p}=0.003)$ for the LF domain of HRV. The values of LF were lower in HTOB patients as compared to $\mathrm{C}$ group $(\mathrm{p}=0.007)$.

The parameters of the heart rate variability LFnu, HF power, HFnu and LF/HF ratio did not change during the stress test (Table 2). There were no significant main effects of HT diagnosis, obesity or their interaction.

Pearson's correlations were computed to determine relationship between the parameters measured. BMI positively correlated with SBP $(\mathrm{r}=0.311 ; \mathrm{p}=0.037)$ and negatively with $\triangle$ SBP $(\mathrm{r}=-0.393, \mathrm{p}=0.008)$. Similarly BF\% positively correlated with SBP $(r=0.325$, $\mathrm{p}=0.029$ ).

Positive correlations were found between baseline HR and adrenaline ( $r=0.487, p=0.001)$ and between HR and adrenaline at the end of the stress procedure $(\mathrm{r}=0.373, \mathrm{p}=0.012)$. SBP at the end of the mental stress task correlated positively with adrenaline $(\mathrm{r}=0.443, \mathrm{p}=0.002)$ and noradrenaline $(\mathrm{r}=0.377, \mathrm{p}=0.011)$ and $\triangle$ SBP positively correlated with $\Delta$ noradrenaline $(\mathrm{r}=0.462, \mathrm{p}=0.001)$. Change in HRxSBP product correlated with $\Delta$ noradrenaline $(\mathrm{r}=0.452, \mathrm{p}=0.002)$.

\section{Discussion}

The present study demonstrated enhanced noradrenaline release in response to mental stress in young untreated patients in early stage of HT compared to that in healthy controls. Patients with HT had increased adrenaline concentrations at baseline as well as during the mental stress test. In obese subjects, baseline SBP was higher than in non-obese subjects independently on HT and the stress-induced increase of SBP was lower compared to that in the lean individuals. Accordingly, $\Delta$ SBP negatively correlated with BMI. Obesity in patients with HT did not lead to a different response of $\mathrm{BP}$ or catecholamine levels in comparison to lean HT subjects, therefore does not have additive effect on sympathoadrenal activity. Thus, our working hypothesis was not confirmed.

Under baseline, non-stress conditions, the patients with HT exhibited increased concentrations of plasma adrenaline compared to normotensive subjects (without any influence of obesity) suggesting enhanced sympathetic activation. Goldstein (1983) performed analytical review and no consensus emerged about whether patients with essential HT showed abnormal sympathetic activity as indicated by plasma catecholamine levels. More recently, there are reports showing differences in baseline catecholamine concentrations consistent (Penesova et al. 2008, Canale et al. 2013) as well as inconsistent (Sherwood et al. 1995, Flaa et al. 2006) with the sympathetic overactivity in HT demonstrating that this issue is not fully understood until now. Our results are in support of higher sympathoadrenal activity in early stage HT.

Exposure to the mental stress in the form of Stroop test induced similar increases in SBP, DBP, HR and plasma adrenaline in all groups of volunteers. These results are in agreement with the data reported by other authors using the same mental stress model (Lindqvist $e t$ al. 1993, Tsai et al. 2003). In contrast, several studies using other models of mental stress (Kohler et al. 1997, Palatini et al. 2011) revealed an enhanced BP reactivity in patients with hypertension. In the present study however the sympathetic overactivity of HT patients was 
manifested by augmented noradrenaline response to the Stroop test, which is in support of the results of Perini et al. (1990) obtained in a study with imbalanced number of subjects in the normotensive and HT groups.

Obese subjects of the present cohort exhibited higher baseline SBP but surprisingly lower responses of the SBP to the mental stress task compared to the lean individuals. The lower reactivity to mental stress task is in discrepancy with the generally accepted opinion on the sympathetic overdrive in obesity (Smith and Minson 2012), however, both enhanced (Canale et al. 2013) and low sympathetic activity (Messina et al. 2013) were reported. It is possible that these inconsistent findings are the result of the combination of higher basal levels of SBP with lower reactivity to stress stimuli. We may hypothesize that unspecific stress effects, which could remain unrecognized, might have contributed differently to the measures in individual studies. Phillips and colleagues (2012) provided additional support for the hypothesis that the blood pressure stress reactivity is lower rather than higher in subjects with obesity. The present results are encouraging further research to search for conditions and mechanisms under which adiposity is related to enhanced and under which conditions with lower sympathetic activity. This would help to find appropriate targets for better prevention and treatment of obesity.

The mental stress task in the form of Stroop test induced a significant rise in the $\operatorname{lnLF}$ of the HRV in the whole sample. This finding represents an enlargement of the observation of an increase in this parameter during the Stroop test in young healthy volunteers of both genders (Visnovcova et al. 2014).

Studies of the relationship between BMI and HRV have reported conflicting results, but to our knowledge, there are no studies on changes in the HRV in response to the Stroop test in obese subjects. There is only one recent study using a mental stress (arithmetic stressor) combined with a physical exercise (Mehta 2014) with consistent results on LF/HF ratio in obese subjects. Present findings indicate that the presence of obesity has no effect on cardiac sympatho-vagal balance in hypertension. The mechanisms responsible for the induction of sympatho-vagal dysbalance by obesity in normotensive subjects remains to be elucidated.

The limitations of the present study include the measurement of plasma catecholamines in venous and not in arterial blood which is considered to be a better mirror of adrenaline and noradrenaline secretion. The small number of patients is counterbalanced by the careful diagnosis and selection of the patients and their controls.

In conclusion, our results are in support of higher sympathoadrenal activity in early stage HT manifested by augmented noradrenaline response to the mental stress test and overall higher adrenaline levels. The present data further demonstrate that obesity does not have any additional effect on sympathoadrenal activity, however obesity is connected with higher systolic blood pressure and modifies the HRV response to mental stress.

\section{Conflict of Interest}

There is no conflict of interest.

\section{Acknowledgements}

The authors appreciate the skillful technical assistance of Ing. Milada Rakicka. This work was supported by the grants of APVV-0028-10 and the project of the University Science Park for Biomedicine Bratislava ITMS 26240220087.

\section{Abbreviations}

ANOVA - analysis of variance

$\mathrm{BF}$ - body fat

$\mathrm{BMI}$ - body mass index

$\mathrm{BP}$ - blood pressure

$\mathrm{C}$ - control subjects

DBP - diastolic blood pressure

ECG - electrocardiography

ESH/ESC - European Society of Hypertension/European

Society of Cardiology

GLM-RM - general linear model repeated measures

$\mathrm{HF}$ - high frequency power

HR - heart rate

HRV - heart rate variability

HT - hypertension, hypertensive subjects

HTOB - hypertensive obese subjects

LF - low frequency power

OB - obese subjects

SBP - systolic blood pressure

$\mathrm{SD}$ - standard deviation

SEM - standard error of mean

SPSS - Statistical Package for Social Science

$\mathrm{TP}$ - total power 


\section{References}

CANALE MP, MANCA di VILlAhERMOSA S, MARTINO G, ROVELlA V, NOCE A, DE LORENZO A, DIDANIELE N: Obesity-related metabolic syndrome: mechanisms of sympathetic overactivity. Int $J$ Endocrinol 2013: 865965, 2013.

ESH/ESC: 2003 European Society of Hypertension-European Society of Cardiology guidelines for the management of arterial hypertension. J Hypertens 21: 1011-1053, 2003.

FLAA A, MUNDAL HH, EIDE I, KJELDSEN S, ROSTRUP M: Sympathetic activity and cardiovascular risk factors in young men in the low, normal, and high blood pressure ranges. Hypertension 47: 396-402, 2006.

FOSSUM E, HOIEGGEN A, REIMS HM, MOAN A, ROSTRUP M, EIDE I, KJELDSEN SE: High screening blood pressure is related to sympathetic nervous system activity. Insulin resistance in healthy young men. Blood Press 13: 89-94, 2004.

GOLDSTEIN DS: Plasma catecholamines and essential hypertension. An analytical review. Hypertension 5: 86-99, 1983.

GOLDSTEIN DS, BENTHO O, PARK MY, SHARABI Y: Low-frequency power of heart rate variability is not a measure of cardiac sympathetic tone but may be a measure of modulation of cardiac autonomic outflows by baroreflexes. Exp Physiol 96: 1255-1261, 2011.

HLAVACOVA N, WAWRUCH M, TISONOVA J, JEZOVA D: Neuroendocrine activation during combined mental and physical stress in women depends on trait anxiety and the phase of the menstrual cycle. Ann N Y Acad Sci 1148: 520-525, 2008.

HUANG CM, CHANG HC, KAO ST, LI TC, WEI CC, CHEN CC, CHEN FJ, TSOU SS: Radial pressure pulse and heart rate variability in normotensive and hypertensive subjects. J Altern Complement Med 17: 945-952, 2011.

JEZOVA D, HLAVACOVA N, MAKATSORI A, DUNCKO R, LODER I, HINGHOFER-SZALKAY H: Increased anxiety induced by listening to unpleasant music during stress exposure is associated with reduced blood pressure and ACTH responses in healthy men. Neuroendocrinology 98: 144-150, 2013.

LAMBERT EA, LAMBERT GW: Stress and its role in sympathetic nervous system activation in hypertension and the metabolic syndrome. Curr Hypertens Rep 13: 244-248, 2011.

LAMBERT E, IKA SARI C, DAWOOD T, NGUYEN J, MCGRANE M, EIKELIS N, CHOPRA R, WONG C, CHATZIVLASTOU K, HEAD G, STRAZNICKY N, ESLER M, SCHLAICH M, LAMBERT G: Sympathetic nervous system activity is associated with obesity-induced subclinical organ damage in young adults. Hypertension 56: 351-358, 2010.

LIN G, XIANG Q, FU X, WANG S, WANG S, CHEN S, SHAO L, ZHAO Y, WANG T: Heart rate variability biofeedback decreases blood pressure in prehypertensive subjects by improving autonomic function and baroreflex. J Altern Complement Med 18: 143-152, 2012.

LINDQVIST M, KAHAN T, MELCHER A, HJEMDAHL P: Cardiovascular and sympatho-adrenal responses to mental stress in primary hypertension. Clin Sci (Lond) 85: 401-409, 1993.

MATSUKAWA T, GOTOH E, UNEDA S, MIYAJIMA E, SHIONOIRI H, TOCHIKUBO O, ISHII M: Augmented sympathetic nerve activity in response to stressors in young borderline hypertensive men. Acta Physiol Scand 141: $157-165,1991$.

MEHTA RK: Impacts of obesity and stress on neuromuscular fatigue development and associated heart rate variability. Int J Obes (Lond) 2014 (Epub ahead of print).

MESSINA G, DE LUCA V, VIGGIANO A, ASCIONE A, IANNACCONE T, CHIEFFI S, MONDA M: Autonomic nervous system in the control of energy balance and body weight: personal contributions. Neurol Res Int 2013: 639280, 2013.

PALATINI P, BRATTI P, PALOMBA D, BONSO E, SALADINI F, BENETTI E, CASIGLIA E: BP reactivity to public speaking in stage 1 hypertension: influence of different task scenarios. Blood Press 20: 290-295, 2011.

PENESOVA A, RADIKOVA Z, CIZMAROVA E, KVETNANSKY R, BLAZICEK P, VLCEK M, KOSKA J, VIGAS M: The role of norepinephrine and insulin resistance in an early stage of hypertension. Ann N Y Acad Sci 1148: 490-494, 2008. 
PERINI C, MULLER FB, RAUCHFLEISCH U, BATTEGAY R, BUHLER FR: Effects of psychological and physical covariates on plasma catecholamines in borderline hypertensives and offspring of hypertensive parents. Clin Exp Hypertens A 12: 137-150, 1990.

PHILLIPS AC, ROSEBOOM TJ, CARROLL D, DE ROOIJ SR: Cardiovascular and cortisol reactions to acute psychological stress and adiposity: cross-sectional and prospective associations in the Dutch Famine Birth Cohort Study. Psychosom Med 74: 699-710, 2012.

PIERCE TW, GRIM RD, KING JS: Cardiovascular reactivity and family history of hypertension: a meta-analysis. Psychophysiology 42: 125-131, 2005.

RADIKOVA Z, PENESOVA A, CIZMAROVA E, HUCKOVA M, KVETNANSKY R, VIGAS M, KOSKA J: Decreased pituitary response to insulin-induced hypoglycaemia in young lean male patients with essential hypertension. J Hum Hypertens 20: 510-516, 2006.

REIMANN M, HAMER M, SCHLAICH MP, MALAN NT, RUEDIGER H, ZIEMSSEN T, MALAN L: Greater cardiovascular reactivity to a cold stimulus is due to higher cold pain perception in black Africans: the Sympathetic Activity and Ambulatory Blood Pressure in Africans (SABPA) study. J Hypertens 30: 2416-2424, 2012.

REIMS HM, SEVRE K, FOSSUM E, MELLEM H, EIDE IK, KJELDSEN SE: Adrenaline during mental stress in relation to fitness, metabolic risk factors and cardiovascular responses in young men. Blood Press 14: 217-226, 2005.

SCHWARTZ CE, DUROCHER JJ, CARTER JR: Neurovascular responses to mental stress in prehypertensive humans. J Appl Physiol 110: 76-82, 2011.

SHERWOOD A, HINDERLITER AL, LIGHT KC: Physiological determinants of hyperreactivity to stress in borderline hypertension. Hypertension 25: 384-390, 1995.

SMITH MM, MINSON CT: Obesity and adipokines: effects on sympathetic overactivity. J Physiol 590: 1787-1801, 2012.

TRACHTA P, DRAPALOVA J, KAVALKOVA P, TOUSKOVA V, CINKAJZLOVA A, LACINOVA Z, MATOULEK M, ZELINKA T, WIDIMSKY J Jr, MRAZ M, HALUZIK M: Three months of regular aerobic exercise in patients with obesity improve systemic subclinical inflammation without major influence on blood pressure and endocrine production of subcutaneous fat. Physiol Res 2: 299-308, 2014.

TREIBER FA, KARAMAK TW, SCHNEIFERMAN N, SHEFFIELD D, KAPUKU G, TAYLOR T: Cardiovascular reactivity and development of preclinical and clinical disease states. Psychosom Med 65: 46-62, 2003.

TSAI PS, YUCHA CB, NICHOLS WW, YARANDI H: Hemodynamics and arterial properties in response to mental stress in individuals with mild hypertension. Psychosom Med 65: 613-619, 2003.

VISNOVCOVA Z, MESTANIK M, JAVORKA M, MOKRA D, GALA M, JURKO A, CALKOVSKA A, TONHAJZEROVA I: Complexity and time asymmetry of heart rate variability are altered in acute mental stress. Physiol Meas 35: 1319-1334, 2014.

VLCEK M, RADIKOVA Z, PENESOVA A, KVETNANSKY R, IMRICH R: Heart rate variability and catecholamines during hypoglycemia and orthostasis. Auton Neurosci 143: 53-57, 2008.

YOUNG JB, MACDONALD IA: Sympathoadrenal activity in human obesity: heterogeneity of findings since 1980. Int J Obes Relat Metab Disord 16: 959-967, 1992. 